ASTHMA

\title{
Vitamin E supplements in asthma: a parallel group randomised placebo controlled trial
}

\author{
P J K Pearson, S A Lewis, J Britton, A Fogarty
}

Thorax 2004;59:652-656. doi: 10.1136/thx.2004.022616

See end of article for authors' affiliations ......................

Correspondence to: Dr A Fogarty, Division of Respiratory Medicine, University of Nottingham, Clinical Science Building, Nottingham City Hospital, Nottingham NG5 IPB, UK; andrew.fogarty@ nottingham.ac.uk

Received 2 February 2004 Accepted 25 March 2004

\begin{abstract}
Background: Increased dietary vitamin $E$ intake is associated with a reduced incidence of asthma, and combinations of antioxidant supplements including vitamin $E$ are effective in reducing ozone induced bronchoconstriction. A study was undertaken to investigate the effect of supplementation with vitamin $E$ for 6 weeks on bronchial hyperresponsiveness in atopic adults with asthma.

Methods: 72 participants from a clinical trial register of adults with asthma were randomised to receive $500 \mathrm{mg}$ natural vitamin $\mathrm{E}$ or matched placebo for 6 weeks in a placebo controlled, double blind parallel group clinical trial. Inclusion criteria included age 18-60 years, maintenance treatment of at least one dose of inhaled corticosteroid per day, a positive skin prick test to one of three common allergens, and bronchial hyperresponsiveness to methacholine (defined as a dose provoking a $20 \%$ fall in forced expiratory volume in 1 second $\left(\mathrm{FEV}_{1}\right)\left(\mathrm{PD}_{20}\right)$ of $\left.12.25 \mu \mathrm{mol}\right)$. Secondary outcomes were $\mathrm{FEV}_{1}$, forced vital capacity, mean morning and evening peak flow, symptom scores, bronchodilator use, and serum immunoglobulin E levels.

Results: In the primary intention to treat analysis the change in $\mathrm{PD}_{20}$ was similar in the vitamin $\mathrm{E}$ and placebo groups with a mean difference of +0.25 doubling doses of methacholine $195 \%$ confidence interval -0.67 to +1.16 greater with vitamin E). There was no effect of vitamin $E$ supplementation on any other measure of asthma control, either in the intention to treat or per protocol analysis. There was also no effect of vitamin E supplementation on serum immunoglobulin levels.

Conclusion: Dietary supplementation with vitamin $\mathrm{E}$ adds no benefit to current standard treatment in adults with mild to moderate asthma.
\end{abstract}

$\mathrm{E}$ pidemiological evidence suggests that antioxidants have a significant effect on the incidence and severity of asthma. ${ }^{12}$ Both dietary ${ }^{3-5}$ and biochemical ${ }^{5} 6$ measures of vitamin $\mathrm{E}$ are lower in adults with asthma than in those without the disease, while higher dietary vitamin E intake is associated with a reduced incidence of asthma. ${ }^{7}$ In addition, four randomised controlled trials of a combination of antioxidant supplements including vitamin $\mathrm{E}$ have shown a reduction in ozone induced bronchoconstriction in those with $^{89}$ and without ${ }^{10-12}$ a diagnosis of asthma. Since these findings suggest that supplementation with vitamin E may also have a beneficial effect on asthma management, we performed a randomised placebo controlled trial of the effect of 6 weeks of regular supplementation with vitamin $E$ on clinical control of asthma.

\section{METHODS}

\section{Participants}

Participants aged 18-60 with physician diagnosed asthma and using at least one dose of inhaled corticosteroid per day were identified from the database of 1300 asthma volunteers held at the City Hospital, Nottingham and invited to take part in the study. Those who responded were contacted by telephone and an initial visit (visit 1) arranged at least 24 hours after the participant received the study information sheet. Ethical approval was granted by the local research ethics committee, City Hospital, Nottingham.

Inclusion criteria were a physician diagnosis of asthma with no deterioration of self-reported asthma symptoms for the previous month, use of at least one dose of inhaled steroid per day, bronchial reactivity to methacholine on two separate occasions, and the presence of atopy. Exclusion criteria were participation in other therapeutic studies in the previous 6 months, current smoking, a smoking history of more than 10 pack years, current use of oral corticosteroids, use of more than $2000 \mu \mathrm{g}$ beclomethasone dipropionate (BDP) equivalent per day ( $1 \mu \mathrm{g}$ BDP taken as equivalent to $1 \mu \mathrm{g}$ budesonide or $0.5 \mu \mathrm{g}$ fluticasone propionate ${ }^{13}$ ), other serious illness, current or planned pregnancy within the study period, the use of vitamin $\mathrm{E}$ supplements within 3 months of screening, and a resting forced expiratory volume in 1 second $\left(\mathrm{FEV}_{1}\right)$ of less than 1 litre. Participants who met these criteria and gave written consent were enrolled in the study.

\section{Study design}

The study was a double blind, randomised, placebo controlled study in adults with asthma of 6 weeks supplementation with vitamin E. Between visits 1 and 2 participants were asked to keep a baseline diary of peak flow measurements, symptom scores, and bronchodilator use for at least 2 weeks. At visit 2 those who had stable asthma, defined as no change in maintenance medication, underwent repeat bronchial reactivity and skin prick testing as at the screening visit to establish a baseline value and confirm eligibility for the study. Participants were given a diary to record peak expiratory flow rate and morning and evening symptoms scores. As far as possible all study visits took place at the same time of day in each individual, after abstaining from short acting bronchodilator inhalers for 4 hours, long acting bronchodilators for 12 hours, and antihistamines for 24 hours. Randomisation (in permuted blocks of six) and dispensing were carried out independently from the recruitment and assessment of participants, and the randomisation code was only broken at the end of the study. Participants were randomised to receive either two vitamin $\mathrm{E}$ capsules (250 mg natural vitamin E ( $D$ - $\alpha$-tocopherol) in soya bean oil (R P Scherer Ltd, Swindon, UK) or two identical placebo 
capsules (gelatine base) for 6 weeks. During the treatment period participants were asked to continue their diary of peak flow measurements, symptom scores, and bronchodilator use. At the end of the intervention period the participants attended for visit 3 and all the measures were repeated. All regular asthma medications including inhaled corticosteroids were continued to be taken at the same dose. Participants experiencing clinical exacerbation of asthma were treated as considered appropriate by their supervising physician including oral corticosteroids if required, returning to their regular pre-exacerbation medication use as soon as possible.

\section{Study measurements}

$\mathrm{FEV}_{1}$ and forced vital capacity (FVC) were measured using a Vitalograph 2120 spirometer (Vitalograph, Buckingham, UK) according to the American Thoracic Society guidelines, ${ }^{14}$ taking the higher of two successive measurements within $200 \mathrm{ml}$ for $\mathrm{FEV}_{1}$ and the best of three technically satisfactory measures for FVC. Peak expiratory flow was recorded as the best of three measurements with a Mini-Wright peak flow meter (Clement Clarke, Harlow, UK) before medication in the morning and evening. Bronchial reactivity was defined as a dose of less than $12.25 \mu \mathrm{mol}$ methacholine to cause a $20 \%$ fall in $\mathrm{FEV}_{1}\left(\mathrm{PD}_{20}\right)$ using the Yan method. ${ }^{15}$ Atopy was defined by at least one allergen skin test response (Dermatophagoides pteronyssinus, cat fur, and grass pollen) $2 \mathrm{~mm}$ greater than control (lancets and allergens from Allergopharma Joachim Ganzer KG, Reinbek, Germany). Asthma symptoms for the night and day were scored on a scale from 0 (no symptoms) to 5 (incapacitating symptoms). Serum samples were taken for immunoglobulin E (IgE) (Pharmacia UniCap) and vitamin E. The samples for $\alpha$ tocopherol analysis were extracted with hexane, prepared by drying down under nitrogen and redissolving in methanol, and then analysed by high performance liquid chromatography. ${ }^{16}$ Dietary data, including vitamin E, were assessed using a semi-quantitative food questionnaire (DietQ version 4.0CN, Tinuviel Software, Warrington, UK) at the baseline and final visits.

\section{Outcome measures}

The primary outcome was change in bronchial responsiveness to methacholine. ${ }^{15}$ Secondary outcomes were change in resting $\mathrm{FEV}_{1}$, FVC, mean morning peak flow, symptom score, bronchodilator use (comparing the 2 week mean value before randomisation with the 2 week mean before finishing the study), and serum IgE.

\section{Statistical analysis and power}

Primary analysis was by intention to treat assuming a deterioration of two doubling doses (DD) in $\mathrm{PD}_{20}$ in all participants withdrawing from the study or increasing treatment, and no change from baseline in secondary outcomes for the individual who withdrew before visit 3 . The methacholine $\mathrm{PD}_{20}$ values were log transformed for all analyses and expressed in terms of change in DD from baseline. $\mathrm{PD}_{20}$ values above the upper limit of measurement ( $12.24 \mu \mathrm{mol}$ methacholine) were censored at $12.24 \mu \mathrm{mol}$. A per protocol analysis was also performed, excluding all participants who failed to complete the protocol (those who withdrew or altered corticosteroid dosage). Each outcome was compared between treatment groups by the Student's $t$ test for parametric data and the Mann-Whitney U test for non-parametric data. Multiple linear regression was used to adjust for baseline differences in sex, baseline inhaled corticosteroid dose, baseline vitamin E intake, and baseline serum vitamin E. In addition, baseline vitamin $\mathrm{E}$ intake and serum vitamin E levels were divided above and below the

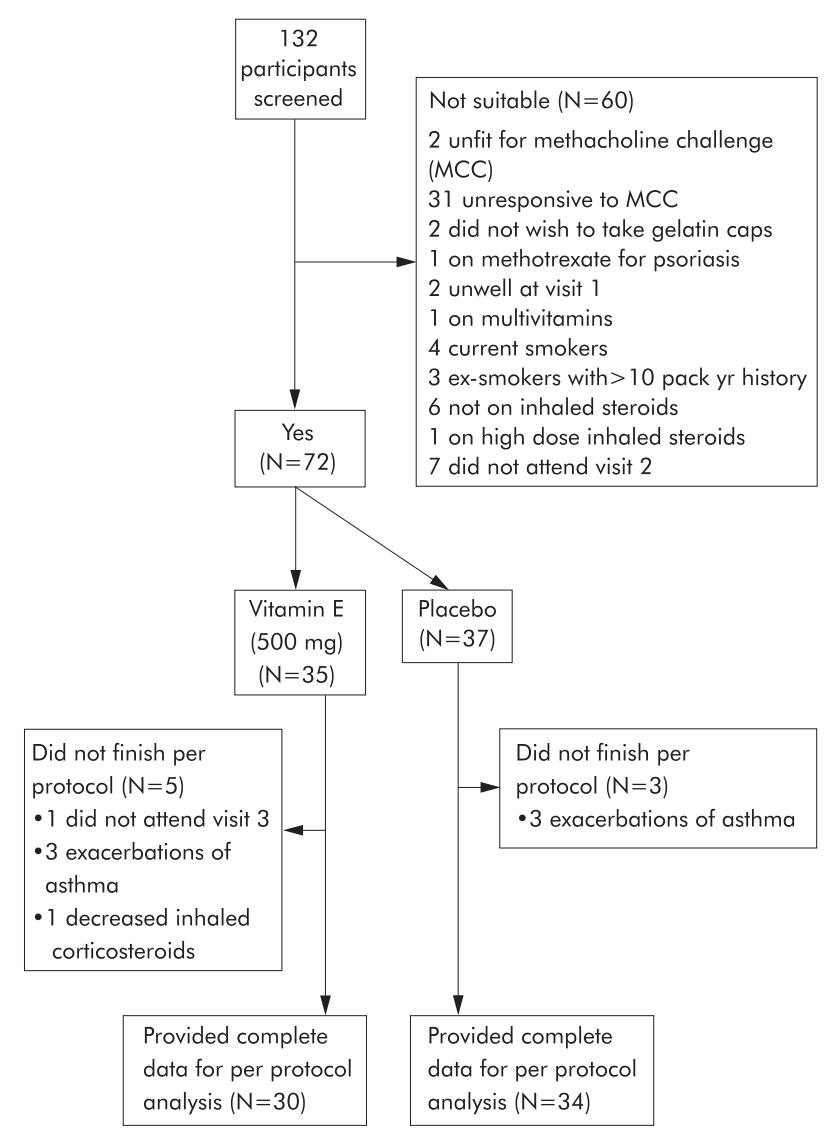

Figure 1 Flow of participants through the study.

median value and an interaction term was added by these variables to look for effect modification.

Our sample size of 35 individuals randomised to each of the vitamin $\mathrm{E}$ and placebo groups was chosen on the assumption of a within person standard deviation for change in bronchial reactivity of $2 \mathrm{DD}$ and for $\mathrm{FEV}_{1}$ of $250 \mathrm{ml}$ in the placebo group, to provide $95 \%$ power to detect a difference of 1.7 DD in bronchial reactivity and $215 \mathrm{ml}$ change in $\mathrm{FEV}_{1}$ from baseline to a statistical level of significance of 0.05 .

Statistical assessment was carried out with the Statistical Package for the Social Sciences (Version 11.5, SPSS Inc, Chicago, USA).

\section{RESULTS}

Participants were recruited between March and November 2002 with follow up through to January 2003. 72 subjects were randomised, 35 to receive vitamin $\mathrm{E}$ supplements and 37 to receive identical placebo (fig l). Eight subjects did not complete the study per protocol (five vitamin E, three placebo) so were included in the intention to treat analysis but not the per protocol analysis. Three participants in each group withdrew due to an exacerbation of their asthma. The characteristics of the vitamin $\mathrm{E}$ and placebo groups were similar at baseline including baseline vitamin $\mathrm{E}$ intake (table 1). Daily dietary vitamin E intake did not change significantly over the period of the study $(p=0.28)$.

At the end of the 6 week intervention period there was a significant increase in serum vitamin $\mathrm{E}$ levels in the treatment group (mean (SD) change +24.7 (12.8) $\mu \mathrm{mol} / \mathrm{l}$ ) compared with placebo (mean (SD) change $+2.0(5.5) \mu \mathrm{mol} /$ l), resulting in a mean difference of $+22.7 \mu \mathrm{mol} / \mathrm{l} \quad(95 \%$ confidence interval $(\mathrm{CI})+18.1$ to +27.3$)$. 
Table 1 Baseline characteristics of study participants

\begin{tabular}{|c|c|c|c|}
\hline & All & Vitamin E group & Placebo group \\
\hline No of participants & 72 & 35 & 37 \\
\hline Mean (SD) age (years) & $47.9(8.9)$ & $48.4(8.4)$ & $47.5(9.4)$ \\
\hline Male, $\mathrm{n}(\%)$ & $33(46)$ & $16(46)$ & $17(46)$ \\
\hline Mean (SD) BMI $\left(\mathrm{kg} / \mathrm{m}^{2}\right)$ & $26.8(7.6)$ & $25.6(4.5)$ & $28.0(9.6)$ \\
\hline Mean (SD) duration of asthma (years) & $26.3(14.1)$ & $24.5(14.4)$ & $28.0(13.7)$ \\
\hline $\begin{array}{l}\text { Median (range) daily inhaled steroid } \\
\text { dose }(\mu \mathrm{g})^{*}\end{array}$ & $400(100-2000)$ & $400(100-2000)$ & $400(200-1000)$ \\
\hline Number on long acting $\beta_{2}$ agonists & 19 & 7 & 12 \\
\hline Mean (SD) FEV 1 (I) & $2.51(0.66)$ & $2.48(0.61)$ & $2.53(0.71)$ \\
\hline Mean (SD) FEV $1 \%$ predicted) & $77(16)$ & $78(17)$ & $77(15)$ \\
\hline Geometric mean (SD) $\mathrm{PD}_{20}$ & $0.77(4.55)$ & $0.86(4.63)$ & $0.69(4.53)$ \\
\hline Mean (SD) morning PEF (l/min) & $416(77)$ & $416(65)$ & $416(88)$ \\
\hline $\begin{array}{l}\text { Median (range) daily bronchodilator use } \\
\text { (puffs/24 hours) }\end{array}$ & $0(0-12)$ & $0(0-12)$ & $0(0-12)$ \\
\hline Median (range) daytime symptom score & $0(0-3)$ & $0(0-3)$ & $0(0-2)$ \\
\hline Median (range) night time symptom score & $0(0-2)$ & $0(0-2)$ & $0(0-2)$ \\
\hline Mean $(S D)$ vitamin $E$ intake $(\mathrm{mg})$ & $7.27(3.55)$ & $6.84(2.50)$ & $7.66(4.29)$ \\
\hline Mean (SD) serum vitamin $E(\mu \mathrm{mol} / \mathrm{I})$ & $26.8(8.2)$ & $27.4(10.4)$ & $26.1(5.4)$ \\
\hline \multicolumn{4}{|c|}{$\begin{array}{l}\mathrm{BMI}=\text { body mass index; } \mathrm{FEV}_{1}=\text { forced expiratory volume in } 1 \text { second; } \mathrm{FVC}=\text { forced vital capacity; } \mathrm{PD}_{20}=\text { dose of } \\
\text { methacholine provoking a fall in } \mathrm{FEV}, \text { of } 20 \% \text { or more; } \mathrm{PEF}=\text { peak expiratory flow. } \\
{ }^{*} \text { Expressed as beclomethasone equivalent dose }(1000 \mu \mathrm{g} \text { budesonide or } 500 \mu \mathrm{g} \text { fluticasone equivalent to } 1000 \mu \mathrm{g} \\
\text { beclomethasone). }\end{array}$} \\
\hline
\end{tabular}

\section{Primary and secondary outcomes}

In the intention to treat analysis there was no difference between those receiving vitamin $\mathrm{E}$ and those receiving placebo in change in bronchial reactivity to methacholine. The mean difference was +0.25 DD methacholine $(95 \%$ CI -0.67 to +1.16 ) for the vitamin E group (mean (SD) +0.08 (2.33) DD) compared with placebo (mean (SD) -0.16 (1.50) DD). Adjusting for any one or all of the baseline parameters did not appreciably alter this result. Using intention to treat analysis there was no difference between the vitamin $\mathrm{E}$ and placebo groups in any of the secondary outcomes of change in $\mathrm{FEV}_{1}, \mathrm{FVC}$, morning peak flow, bronchodilator use, night time or day time symptom scores, serum IgE, or loss of atopic response (table 2).

In the per protocol analysis, excluding those who failed to complete or who increased or decreased treatment, there were also no significant differences between those who received vitamin $\mathrm{E}$ or placebo supplements in bronchial reactivity, change in $\mathrm{FEV}_{1}, \mathrm{FVC}$, morning peak flow, bronchodilator use, night time or day time symptom scores, serum IgE, or loss of atopic response (table 3). There were no significant interactions with baseline vitamin $\mathrm{E}$ intake or serum level in either the intention to treat or per protocol analyses.

\section{DISCUSSION}

The aim of this study was to determine whether dietary supplementation with vitamin $\mathrm{E}$ in adults with mild to moderate asthma using regular inhaled corticosteroids would result in an improvement in bronchial reactivity or other measures of asthma control. Our findings show that daily administration of $500 \mathrm{mg}$ natural vitamin $\mathrm{E}$ for 6 weeks had no effect on asthma.

Our validation data suggest that adherence with allocated treatment was good, as shown by the $90 \%$ increase in serum vitamin $\mathrm{E}$ in this group. Our findings are also unlikely to be attributable to low study power. We determined our sample size to detect an improvement of 1.7 DD methacholine and, although the number who provided complete data was 64 (which was slightly less than the 70 participants needed according to our power calculation), this small difference in

Table 2 Intention to treat analysis of change in primary and secondary outcome measures over 6 weeks in the vitamin $E$ and placebo groups

\begin{tabular}{|c|c|c|c|c|}
\hline Outcome & $\begin{array}{l}\text { Vitamin } E \\
(n=35)\end{array}$ & $\begin{array}{l}\text { Placebo } \\
(n=37)\end{array}$ &  & p value \\
\hline $\begin{array}{l}\text { Mean (SD) change in bronchial } \\
\text { reactivity in doubling doses }\end{array}$ & $+0.08(2.33)$ & $-0.16(1.50)$ & $+0.25(-0.67$ to +1.16$)$ & 0.59 \\
\hline Mean (SD) change in $\mathrm{FEV}_{1}(\mathrm{ml})$ & $+37(163)$ & $-26(203)$ & $+63(-24$ to +149$)$ & 0.16 \\
\hline Mean (SD) change in FVC (ml) & +27 (194) & $-18(302)$ & $+46(-76$ to +165$)$ & 0.46 \\
\hline $\begin{array}{l}\text { Mean (SD) change in am peak } \\
\text { flow }(I / \mathrm{min})\end{array}$ & $+1(24)$ & $-4(21)$ & $+5(-6$ to +16$)$ & 0.36 \\
\hline $\begin{array}{l}\text { Median (range) change in } \\
\text { bronchodilator use (puffs/day) } \dagger\end{array}$ & $0(-3$ to +4$)$ & $0(-8$ to +5$)$ & 0 ฯ & 0.49 \\
\hline $\begin{array}{l}\text { Median (range) change in } \\
\text { daytime symptom score }\end{array}$ & $0(-1$ to +1$)$ & $0(-1$ to 2$)$ & 0 & 0.58 \\
\hline $\begin{array}{l}\text { Median (range) change in median } \\
\text { night time symptom score }\end{array}$ & $0(-2$ to +1$)$ & $0(-1$ to +2.5$)$ & 0 & 0.93 \\
\hline $\begin{array}{l}\text { Mean (SD) ratio of change } \\
\text { in } \lg \mathrm{E}^{*}\end{array}$ & $0.99(1.22)$ & $0.99(1.54)$ & $1.01(0.86$ to 1.18$)$ & 0.95 \\
\hline Loss of atopic responseł & $7 / 35(20 \%)$ & $5 / 37(14 \%)$ & $6 \%(-11$ to 24$)$ & 0.46 \\
\hline \multicolumn{5}{|c|}{$\begin{array}{l}\text { Visit } 3 \text { data not available for one participant so baseline data used for visit } 3 \text {. } \\
\text { FEV } 1 \text { = forced expiratory volume in } 1 \text { second; } F V C=\text { forced vital capacity. } \\
\text { *Differences in log terms for lgE were anti-logged to give ratio of lgE values, final/baseline and vitamin E/placebo. } \\
\text { †Analysis by the Mann-Whitney U test with median change. } \\
\text { †Analysis by } \chi^{2} \text { test. } \\
\text { - Confidence intervals not calculated for difference in medians. }\end{array}$} \\
\hline
\end{tabular}


Table 3 Per protocol analysis of change in primary and secondary outcome measures over 6 weeks in the vitamin E and placebo groups

\begin{tabular}{|c|c|c|c|c|}
\hline Outcome & $\begin{array}{l}\text { Vitamin E } \\
(n=30)\end{array}$ & $\begin{array}{l}\text { Placebo } \\
(n=34)\end{array}$ & Difference ${ }^{*}(95 \% \mathrm{Cl})$ & $\mathrm{p}$ value \\
\hline $\begin{array}{l}\text { Mean (SD) change in bronchial } \\
\text { reactivity (DD) }\end{array}$ & $+0.38(2.38)$ & $0.00(1.45)$ & $+0.38(-0.59$ to +1.35$)$ & 0.44 \\
\hline Mean (SD) change in $\mathrm{FEV}_{1}(\mathrm{ml})$ & $+26(138)$ & $-27(212)$ & $+53(-38$ to +143$)$ & 0.25 \\
\hline Mean (SD) change in FVC (ml) & +25 (177) & $-16(313)$ & $+41(-88$ to +170$)$ & 0.53 \\
\hline $\begin{array}{l}\text { Mean (SD) change in AM peak } \\
\text { flow (I/min) }\end{array}$ & $+1(25)$ & $-3(21)$ & $+4(-7$ to +16$)$ & 0.48 \\
\hline $\begin{array}{l}\text { Median (range) change in } \\
\text { bronchodilator use (puffs/day)t }\end{array}$ & $0(-3$ to +2$)$ & $0(-8$ to +5$)$ & 0 & 0.65 \\
\hline $\begin{array}{l}\text { Median (range) change in } \\
\text { daytime symptom score }\end{array}$ & $0(-1$ to +1$)$ & $0(-1$ to +2$)$ & 0 & 0.68 \\
\hline $\begin{array}{l}\text { Median (range) change in night } \\
\text { time symptom score }\end{array}$ & $0(-2$ to +1$)$ & $0(-1$ to +2.5$)$ & 0 & 0.92 \\
\hline $\begin{array}{l}\text { Mean (SD) change in lgE* ratio } \\
\text { Loss of atopic responsef }\end{array}$ & $\begin{array}{l}0.98(1.24) \\
7 / 30(23 \%)\end{array}$ & $\begin{array}{l}0.95(1.54) \\
5 / 34(15 \%)\end{array}$ & $\begin{array}{l}1.03(0.87 \text { to } 1.23) \\
9 \%(-10 \text { to } 28)\end{array}$ & $\begin{array}{l}0.73 \\
0.57\end{array}$ \\
\hline \multicolumn{5}{|c|}{$\begin{array}{l}\text { FEV } V_{1}=\text { forced expiratory volume in } 1 \text { second; } F V C=\text { forced vital capacity. } \\
\text { *Differences in log terms for IgE were anti-logged to give ratio of IgE values, final/baseline and vitamin } E / \text { placebo. } \\
\text { †Analysis by the Mann-Whitney } U \text { test with median change. } \\
\text { †Analysis by } \chi^{2} \text { test. } \\
\text { TConfidence intervals not calculated for difference in medians. }\end{array}$} \\
\hline
\end{tabular}

power is insufficient to invalidate the negative result of this study. We are, however, unable to exclude the possibility that vitamin $\mathrm{E}$ has an effect but of smaller magnitude, and our 95\% confidence interval suggests that the true effect is unlikely to be greater than an increase of $1.16 \mathrm{DD}$ in $\mathrm{PD}_{20}$.

Our finding conflicts with the available epidemiological evidence and we need to consider why we did not see an effect of vitamin E supplements on asthma control. It is possible that vitamin $\mathrm{E}$ is effective only in those with a low dietary vitamin $\mathrm{E}$ intake. The daily vitamin $\mathrm{E}$ intake in our study population was only $10 \%$ less than the mean value for the UK, ${ }^{17}$ but restricting the analysis to those who consumed less than half the median intake for the study did not affect our findings. We therefore consider this explanation to be unlikely. It is possible that the observational epidemiological evidence suggesting that vitamin E may be important in the development of asthma ${ }^{3-7}$ has arisen from confounding by other associated nutrients and lifestyle exposures. In addition, dietary vitamin $\mathrm{E}$ is correlated with dietary vitamin $\mathrm{C}^{18}$ which is required to permit optimal antioxidant activity, ${ }^{19}$ and it may be that supplementation with vitamin $\mathrm{E}$ and vitamin $\mathrm{C}$ is required to see a beneficial effect on asthma control. This is supported by the intervention studies of vitamin $\mathrm{E}$ and vitamin $\mathrm{C}$ with ${ }^{10}{ }^{11}$ and without ${ }^{820} \beta$-carotene which have shown a beneficial effect on ozone induced bronchial hyperresponsiveness, the beneficial effect being seen in as little as 4 weeks. ${ }^{8}$ Although these findings suggest that the duration of our study was adequate, we also cannot exclude the possibility that a beneficial response may have become evident after a longer period of intervention. In addition, it is possible that studying a population of adults with asthma currently being treated with regular inhaled corticosteroids reduced our ability to detect an effect of vitamin E supplements, and we cannot discount the possibility that vitamin E may have an effect in steroid naive asthmatics. It is important to stress that our study subjects were non-smokers and so it is impossible to generalise our findings to those who are exposed to a larger exogenous oxidant burden either by cigarette smoking ${ }^{21}$ or exposure to higher levels of environmental ozone. ${ }^{22}$

The implication of our study is therefore that dietary supplementation of vitamin E for 6 weeks has no effect on asthma control. Since we have previously found a similar outcome for vitamin $\mathrm{C}$ and magnesium supplements in asthma, ${ }^{23}$ our trials indicate that these single nutrients are not effective. Future studies of antioxidants should therefore perhaps consider using combinations of antioxidants, whether in a synthetic preparation or in the form of whole foods such as fruit.

\section{ACKNOWLEDGEMENTS}

The authors thank Ms Sarah Pacey for dispensing the supplements and Dr Nigel Lawson for supervising the biochemical assays.

\section{Authors' affiliations}

P J K Pearson, S A Lewis, A Fogarty, Division of Respiratory Medicine, University of Nottingham, Clinical Science Building, Nottingham City Hospital, Nottingham NG5 1PB, UK

J Britton, Division of Epidemiology and Public Health, University of Nottingham, Clinical Science Building, Nottingham City Hospital, Nottingham NG5 1PB, UK

Funding from National Asthma Campaign. The vitamin E tablets were provided by RP Scherer Ltd.

\section{REFERENCES}

1 Smit H, Grievink L, Tabak C. Dietary influences on chronic obstructive lung disease and asthma: a review of the epidemiological evidence. Proc Nutr Soc 1999;58:309-19

2 Fogarty A, Britton J. The role of diet in the aetiology of asthma. Clin Exp Allergy 2000:30:615-27.

3 Hijazi N, Abalkhail B, Seaton A. Diet and childhood asthma in a society in transition: a study in urban and rural Saudi Arabia. Thorax 2000;55:775-9.

4 Baker J, Tunnicliffe W, Duncanson R, et al. Dietary antioxidants and magnesium in type 1 brittle asthma: a case control study. Thorax 1999;54:115-8.

5 Bodner C, Godden D, Brown K, et al. Antioxidant intake and adult-onset wheeze: a case-control study. Eur Respir J 1999;13:22-30.

6 Kelly F, Mudway I, Blomberg A, et al. Altered lung antioxidant status in patients with mild asthma. Lancet 1999;354:482-3.

7 Troisi R, Willett W, Weiss S, et al. A prospective study of diet and adult-onset asthma. Am J Respir Crit Care Med 1995;151:1401-8.

8 Trenga C, Koenig J, Williams P. Dietary antioxidants and ozone-induced bronchial hyperresponsiveness in adults with asthma. Arch Environ Health 2001;56:242-9.

9 Romieu I, Sienra-Monge J, Ramirez-Aguilar M, et al. Antioxidant supplementation and lung function among children with asthma exposed to high levels of air pollutants. Am J Respir Crit Care Med 2002;166:703-9.

10 Romieu I, Meneses F, Ramirez M, et al. Antioxidant supplementation and respiratory functions among workers exposed to high levels of ozone. Am J Respir Crit Care Med 1998;158:226-32.

11 Grievink L, Jansen S, Van't Veer P, et al. Acute effects of ozone on pulmonary function of cyclists receiving antioxidant supplements. Occup Environ Med 1998;55:13-7.

12 Grievink L, Ziilstra A, KeX, et al. Double-blind intervention trial on modulation of ozone effects on pulmonary function by antioxidant supplements. Am J Epidemiol 1999;149:306-14.

13 Barnes N, Marone G, Maria G, et al. A comparison of fluticasone propionate, $1 \mathrm{mg}$ daily, with beclomethasone dipropionate, $2 \mathrm{mg}$ daily, in the treatment of severe asthma. Eur Respir J 2001;6:877-84 
14 American Thoracic Society. Standardisation of spirometry-1994 update. Am J Respir Crit Care Med 1994; 152:1 107-36.

15 Yan K, Salome C, Woolcock A. A rapid method for measurement of bronchial responsiveness. Thorax 1983;38:760-5.

16 Bieri J, Tolliver T, Catignani G. Simultaneous determination of alphatocopherol and retinol in plasma or red cells by high pressure liquid chromatography. Am J Clin Nutr 1979;32:2143-9.

17 Anon. Report of the Cardiovascular Review Group Committee on the Medical Aspects of Food Policy. Nutritional aspects of cardiovascular disease 2001:69-83.

18 Britton J, Pavord I, Richards K, et al. Dietary antioxidant vitamin intake and lung function in the general population. Am J Respir Crit Care Med 1995; 151:1383-7.
19 Chan A. Partners in defense, vitamin E and vitamin C. Can J Physiol Pharmacol 1993;71:725-31.

20 Butland B, Strachan D, Anderson H. Fresh fruit intake and asthma symptoms in young British adults: confounding or effect modification by smoking? Eur Respir J 1999;13:744-50.

21 Rahman I, Morrison D, Donaldson K, et al. Systemic oxidative stress in asthma, COPD and smokers. Am J Respir Crit Care Med 1996;154:1055-60.

22 McConnell R, Berhane K, Gilliland F, et al. Asthma in exercising children exposed to ozone. Lancet 2002;359:386-91.

23 Fogarty A, Lewis S, Scrivener S, et al. Oral magnesium and vitamin C supplements in asthma: a parallel group randomised placebo-controlled trial. Clin Exp Allergy 2003;33:1355-9.

\section{LUNG ALERT}

\section{Chronic thromboembolic pulmonary hypertension: an under-recognised consequence of $\mathrm{PE}$}

$\Delta$ Pengo V, Lensing AWA, Prins MH, et al. Incidence of chronic thromboembolic pulmonary hypertension after pulmonary embolism. N Engl J Med 2004;350:2257-64

$\mathrm{T}$ he risk of developing chronic thromboembolic pulmonary hypertension (CTPH) following pulmonary embolism (PE) has not been clearly defined. In this prospective study 223 patients diagnosed with a first symptomatic PE were followed for a median period of 94.3 months. Patients with conditions predisposing to non-thromboembolic pulmonary hypertension were excluded from the study, as were those with a previous PE or deep vein thrombosis (DVT). Patients who developed unexplained breathlessness during follow up were investigated with transthoracic echocardiography. V/Q scanning and pulmonary angiography followed when echocardiography suggested CTPH. CTPH was diagnosed on the basis of pulmonary artery pressures and angiographic findings. Seven patients developed CTPH. The cumulative incidence of CTPH at 6 months was 1\%, at 1 year $3.1 \%$, and at 2 years $3.8 \%$. No cases of CTPH presented more than 2 years after the initial diagnosis of PE.

A further 82 patients with acute PE and previous thromboembolism were included in an analysis of risk factors for CTPH; 11 of these patients developed CTPH. Risk factors included previous $\mathrm{PE}$, or PE presenting at a younger age, with a larger perfusion defect, or in the absence of an identifiable risk factor.

This study suggests that CTPH occurs earlier and more frequently than previously estimated. As a serious and relatively common complication of PE, more attention should be focused on prevention, early detection, and treatment. Prevention of recurrent PE by improvements in the treatment of PE and DVT should reduce the incidence of CTPH.

H C Barker Specialist Registrar, Basildon Hospital, Essex, UK; barkerhc@yahoo.com 